\title{
ALK alterations in adult renal cell carcinoma: frequency, clinicopathologic features and outcome in a large series of consecutively treated patients
}

\author{
William R Sukov ${ }^{1}$, Jennelle C Hodge ${ }^{1}$, Christine M Lohse ${ }^{2}$, Monica K Akre ${ }^{1}$, \\ Bradley C Leibovich ${ }^{3}$, R Houston Thompson ${ }^{3}$ and John C Cheville ${ }^{1}$ \\ ${ }^{1}$ Department of Laboratory Medicine \& Pathology, Mayo Clinic, Rochester, MN, USA; ${ }^{2}$ Division of Biomedical \\ Statistics \& Informatics, Mayo Clinic, Rochester, MN, USA and ${ }^{3}$ Department of Urology, Mayo Clinic,
} Rochester, MN, USA

\begin{abstract}
Chromosomal rearrangements involving the anaplastic lymphoma kinase gene $(A L K)$ at 2 p23 result in fusion with various partner genes leading to aberrant production of oncogenic protein products in multiple tumor types. Recently, the ALK protein inhibitor crizotinib was shown to be an effective therapy in patients with ALKrearranged non-small cell lung cancer. The goal of this study was to determine the frequency of $A L K$ alterations in adult renal cell carcinoma (RCC) and define associated clinicopathologic features and outcome. RCCs from a cohort of 534 consecutive surgically treated adult patients were analyzed for alterations of $A L K$ by fluorescence in situ hybridization. ALK rearrangements were identified in 2 of $534(<1 \%)$ RCCs. Both showed similar histologic features and the patients had a poor outcome. ALK copy number gain was identified in $54(10 \%)$ RCCs. In clear cell type RCC (CCRCC), ALK copy number gain was significantly associated with tumor size $(P=0.02)$ and nuclear grade $(P<0.001)$, and with a worse 10 -year cancer-specific survival vs similar patients lacking $A L K$ copy number gain $(P=0.03)$. $A L K$ rearrangement is rare in adult $R C C$ but may be associated with distinct histological features and poor outcome. Another potential mechanism to elevate ALK expression, increased $A L K$ gene copy number, was observed in $10 \%$ of adult CCRCC, where it is associated with a higher tumor grade and poorer outcome. Additional studies are necessary to determine whether patients RCCs with ALK rearrangement and/or those with an increase in ALK copy number would benefit from ALK inhibitor treatment. Modern Pathology (2012) 25, 1516-1525; doi:10.1038/modpathol.2012.107; published online 29 June 2012
\end{abstract}

Keywords: adult; ALK; cytogenetics; renal cell carcinoma

Chromosomal rearrangements involving the anaplastic lymphoma kinase gene $(A L K)$ at 2 p23 were first recognized in anaplastic large cell lymphoma. ${ }^{1}$ The characteristic translocation was shown to result in fusion of the $3^{\prime}$ portion of $A L K$ with the $5^{\prime}$ portion of NPM1 at $5 \mathrm{q} 35$ to produce a chimeric oncogene. ${ }^{2}$ Recurrent rearrangements of $A L K$ have since been described with numerous partner genes in anaplastic lymphoma and other hematolymphoid malignancies

Correspondence: Dr WR Sukov, MD, Department of Laboratory Medicine and Pathology, Mayo Clinic, 200 First St, SE, Rochester, MN 55905, USA.

E-mail: sukov.william@mayo.edu

Received 11 October 2011; revised 2 April 2012; accepted 15 May 2012; published online 29 June 2012 as well as in solid tumors such as inflammatory myofibroblastic tumors, esophageal squamous cell carcinoma, breast carcinoma, colonic adenocarcinoma, lung adenocarcinoma and, recently, pediatric renal cell carcinoma (RCC). ${ }^{3-9}$

The ALK protein is a membrane-associated tyrosine kinase belonging to the insulin receptor superfamily. Outside of the embryonic state, ALK expression is normally confined to the central nervous system. ${ }^{2}$ Chromosomal rearrangements resulting in $A L K$ gene fusion lead to aberrant ALK activation by formation of chimeric protein products, which are expressed in a cytoplasmic and/or membranous distribution, depending on the fusion partner. The ALK fusion products have significant oncogenic activity. ${ }^{10-14}$ Because of the expression 
pattern, ALK fusion products have become an enticing chemotherapeutic target. Recently, the ALK inhibitor crizotinib was shown to be an effective therapy in patients with $A L K$-rearranged non-small cell lung cancers. ${ }^{15-17}$

The present study involved screening RCCs from a large cohort of surgically treated adult patients from a single institution for $A L K$ alterations. The goal was to define the frequency of $A L K$ alterations, including rearrangements and copy number gain, in a comprehensive manner. Additionally, we wished to identify the associated clinical and pathological features as well as any relationship between patient outcome and $A L K$ locus alteration.

\section{Materials and methods}

\section{Patient Selection}

The study was first approved by the Institutional Review Board. Using the Mayo Clinic Nephrectomy Registry, 647 patients treated with radical or partial nephrectomy for unilateral, sporadic, clear cell type RCC (CCRCC) or PRCC were identified. This included 334 patients with clear-cell RCC consecutively treated from 1990 to 1994 and 313 patients with PRCC consecutively treated from 1970 to 2002.

\section{Clinical and Pathological Features}

Clinical features studied included age at surgery, gender, and symptoms at diagnosis. Patients with a palpable mass, abdominal discomfort, gross hematuria, acute onset varicocele, or constitutional symptoms including rash, sweats, weight loss, fatigue, early satiety, or anorexia were considered symptomatic at diagnosis. Pathologic features studied included histologic subtype, tumor size, the 2010 primary tumor, regional lymph node, and distant metastases classifications, nuclear grade, coagulative tumor necrosis, sarcomatoid differentiation, and multifocality. A urologic pathologist (JCC) reviewed the microscopic slides from all tumor specimens for the pathologic features of interest. Grade was based only on nucleolar prominence other than grade 4 . Tumors with nucleoli readily visible at $\times 100$ magnification, filling at least one field, were classified as grade 3 . Tumors with nucleoli visible at $\times 200$ magnification in one field were considered grade 2 . Tumors with inconspicuous nucleoli were classified as grade 1. Tumors were considered grade 4 if sarcomatoid differentiation was present or the lesion contained markedly pleomorphic or multinucleate giant cells. SSIGN scores were calculated for patients with CCRCC. ${ }^{18}$ Vital status for patients in the Nephrectomy Registry is updated yearly through a review of medical records and correspondence with patients and their local physicians.

\section{Tissue Preparation and ALK FISH Analysis}

Tissue microarrays (TMAs) were constructed using formalin-fixed, paraffin-embedded tumor samples from all 808 patients. For each tumor, a representative tissue block was selected based on review of the $\mathrm{H} \& \mathrm{E}$ sections, and four, $0.6 \mathrm{~mm}$ cores of tumor were taken from each patient block and placed in a recipient block. Non-neoplastic kidney tissue cores were also incorporated to serve as location markers and control tissues. From the TMAs, $5 \mu \mathrm{m}$ sections were cut and slides prepared for fluorescence in situ hybridization (FISH) analysis. Slides were hybridized with a commercially available dual-color break-apart ALK FISH probe set (Abbott Molecular, Abbott Park, IL, USA) according to the previously established protocols.

FISH patterns were established by assessment of 200 interphase tumor nuclei. If the tissue was not sufficient to analyze 200 nuclei or the signals were not interpretable, the tumor was removed from the study. Values for gain of intact $A L K$ copies (denoted as $\mathrm{F}$ for fusion signal) were reported if at least $5 \%$ of the tumor nuclei showed that particular number of additional fusion signals. For example, a tumor was denoted as $2-4 \mathrm{~F}$ that had $4 \mathrm{~F}$ signals in 10 of 200 nuclei $(5 \%)$, 3F signals in 30 of 200 nuclei $(15 \%)$, and $2 \mathrm{~F}$ signals in the remaining nuclei. Alternatively, a tumor with 2 of 200 nuclei $(1 \%)$ showing $8 \mathrm{~F}$ signals and the remaining nuclei having $3 \mathrm{~F}$ signals was given a score of $3 \mathrm{~F}$. The $5 \%$ value was selected to reduce the fusion signal artifact due to nuclear overlap while maintaining sensitivity for the presence of additional ALK genes in a small subset of tumor cells due to tumor heterogeneity. Rearrangement of $A L K$ was considered present if $\geq 15 \%$ of nuclei had a FISH signal pattern, indicating split of the $A L K$ locus (1R1G1F). This $15 \%$ cutoff was based on clinical validation of the $A L K$ probe for use on paraffin-embedded tissue sections in the Mayo cytogenetics laboratory.

For cases that showed $A L K$ signal split, FISH was repeated on whole sections cut from the original paraffin-embedded tumor blocks to confirm the $A L K$ rearrangement pattern and determine if intratumoral FISH signal heterogeneity was present.

In addition, whole sections of tumor were interrogated for rearrangements of TFE3 by FISH using a homebrew dual color break-apart probe set. The TFE3 probe set was constructed with bacterial artificial chromosomes selected using the University of California Santa Cruz Biotechnology Genome Browser and Database (http://genome.ucsc.edu, genome assembly hg18), and then obtained from Invitrogen (Carlsbad, CA, USA). DNA was isolated from bacterial cultures by a Plasmid Maxi Kit (QIAGEN, Valencia, CA, USA) and fluorescently 
labeled via nick translation (Abbott Molecular, Des Plaines, IL, USA). Clone specificity was verified by PCR and by FISH on metaphases from normal male blood specimens. Once individually validated, the clones were combined for use as a probe set. The $3^{\prime}$ portion of TFE3 is detected by RP11-416B14 and RP11-1137J13 (273 kb total size) labeled in SpectrumGreen and the $5^{\prime}$ portion of TFE3 is covered by RP11-1037C20 and RP11-315L18 (416 kb total size) labeled in SpectrumOrange. For each tumor, 200 interphase nuclei were scored.

\section{Immunohistochemistry}

Immunohistochemistry was performed according to the manufacturer's protocol on formalin-fixed, paraffin-embedded tumor tissue from the two RCCs showing $A L K$ rearrangement by FISH (patients 1 and 2) using the following antibodies directed against the following antigens: ALK protein/CD246 (Dako, Carpinteria, CA, USA); CD10 (Novacastra, Newcastle Upon Tyne, UK); keratin AE1/AE3 (Dako); CAM5.2 (Becton Dickinson Biosciences, Franklin Lakes, NJ, USA); keratin 7 (Dako); HMB45 (Dako); Melan A (Dako); Napsin A (Novacastra); P504S (Biocare Medical, Concord, CA, USA); vimentin (Dako).

\section{Statistical Methods}

Comparisons of clinical and pathological features were evaluated using Wilcoxon rank sum, $\chi^{2}$, and Fisher's exact tests. Overall and cancer-specific survivals were estimated using the Kaplan-Meier method and compared using log-rank tests. Associations with death from any cause and death from RCC were further evaluated using Cox proportional hazards regression models and summarized with hazard ratios and 95\% confidence intervals (CIs). Statistical analyses were performed using the SAS software package (SAS Institute, Cary, NC, USA). All tests were two-sided and $P$-values $<0.05$ were considered statistically significant.

\section{Results}

Of the 647 tumors studied, ALK FISH assessment was successful in 534 tumors consisting of 250 CCRCC and 284 PRCC. FISH analysis was unsuccessful in 113 tumors (84 CCRCC and 29 PRCC), primarily due to insufficient tumor tissue in the TMA resulting from loss of cores on sectioning. Among patients with PRCC, those with an unsuccessful assessment were less likely to have necrosis compared with those with successful assessments ( $24 \%$ vs $50 \% ; P=0.009$ ). Within each subtype, none of the other clinical or pathological features studied were significantly different between those with successful and unsuccessful assessments of ALK alterations. Therefore, FISH success rate was not

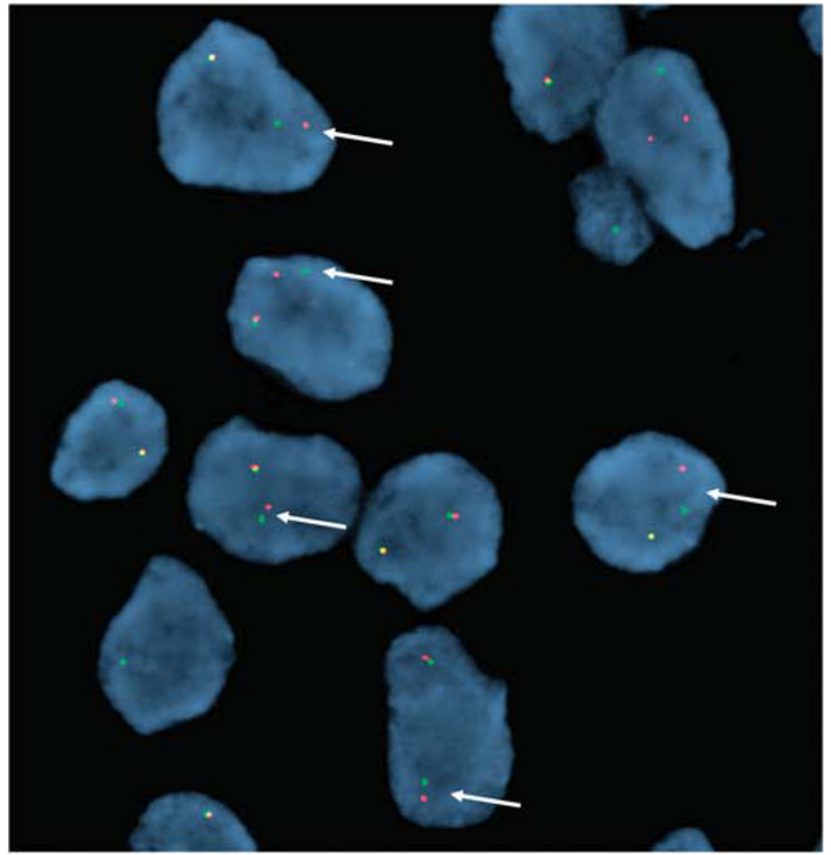

Figure 1 Interphase fluorescence in situ hybridization to identify the rearrangement of anaplastic lymphoma kinase $(A L K)$ using a commercially available $A L K$ break-apart probe (Abbott Molecular) on the tumor from patient 1. Abnormal tumor cells show one red $(\mathrm{R})$, one green $(\mathrm{G})$, and one fusion $(\mathrm{F})$ signal pattern indicating one rearranged $A L K$ gene (white arrows) and one intact $A L K$ gene.

likely to have biased the sample population with regard to tumor features.

\section{ALK Rearrangement}

Rearrangement of the $A L K$ gene was identified in 2 of 534 RCCs. Both tumors were originally diagnosed as PRCC. By FISH, both showed a 1R1G1F signal pattern indicating one rearranged $A L K$ locus and one intact $A L K$ locus (Figure 1). Because of the small number of positive cases, further statistical analysis with regard to clinical features was not possible. However, clinical information on both the patients was available (Table 1). Both the patients had poor clinical outcomes progressing to death from disease in $<5$ years.

Histologically, both tumors with $A L K$ rearrangement had very similar features. The tumor from patient 1 demonstrated a papillary architecture (Figure 2a) and was comprised predominantly by cells with abundant clear to slightly eosinophilic cytoplasm and nuclei with irregular contours and indistinct to small nucleoli. Psammoma bodies and foamy macrophages were present (Figure $2 b$ and $c$ ). Coagulative necrosis was not observed. The tumor from patient 2 was, in some areas, nearly histologically identical to the tumor from patient 1 , also showing papillary structures lined by cells with abundant clear to eosinophilic cytoplasm (Figure 2d). These areas had marked hemosiderin deposition and occasional psammoma bodies. Also 
present were areas with papillary structures lined by cells with scant cytoplasm and small nuclei with inconspicuous nucleoli (Figure 2e). Cells in these areas lined the papillary structures in a single layer. In addition, there were areas showing a solid growth pattern where the tumors cells had primarily eosinophilic cytoplasm and the nuclei were larger with more prominent nucleoli (Figure 2f). The transition between histologically distinct regions was abrupt (Figure 2g). This tumor also had significant coagulative necrosis.

Confirmatory $A L K$ FISH analysis on whole tumor sections showed a $1 \mathrm{R} 1 \mathrm{G} 1 \mathrm{~F}$ signal pattern that was present uniformly throughout all cells in both tumors, even within both the histologically distinct regions of the tumor from patient 2. Immunohistochemistry

Table 1 Clinical and pathological results for patients with $A L K$-rearranged renal cell carcinoma

\begin{tabular}{llllcccccccccc}
\hline Patient & Age & Gender & RCC subtype & $\begin{array}{c}\text { Tumor } \\
\text { size (cm) }\end{array}$ & $p T^{\mathrm{a}}$ & $p N^{\mathrm{a}}$ & $M^{\mathrm{a}}$ & Grade & Necrosis & $\begin{array}{c}\text { Sarcomatoid } \\
\text { features }\end{array}$ & $\begin{array}{c}\text { Multifocal } \\
\text { Years to death } \\
\text { from RCC }\end{array}$ \\
\hline 1 & 61 & Male & Papillary & 5 & 1B & $\mathrm{X}$ & 0 & 2 & No & No & No & 4 \\
2 & 59 & Male & Papillary & 5.5 & $1 \mathrm{~B}$ & $\mathrm{X}$ & 0 & 3 & Yes & No & No & 1.4 \\
\hline
\end{tabular}

Abbreviations: ALK, anaplastic lymphoma kinase; RCC, renal cell carcinoma, X, not assessed.

${ }^{\mathrm{a}}$ Pathological staging based on the American Joint Committee on Cancer Staging, 7th edition, 2010.
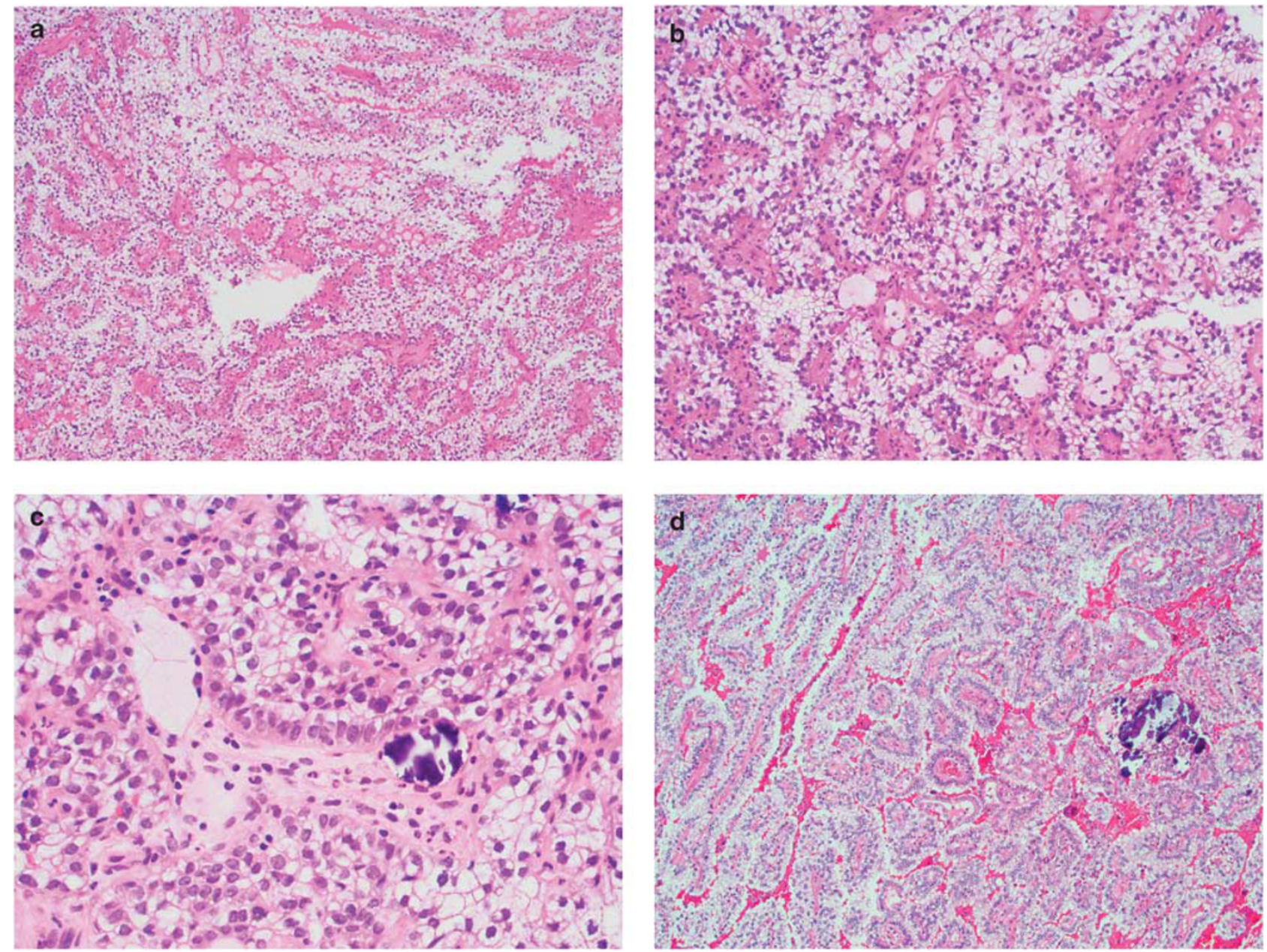

Figure 2 Histological features of renal cell carcinomas with anaplastic lymphoma kinase $(A L K)$ rearrangements. The tumor from patient 1 showed a papillary architecture with papillae lined by cells with clear to eosinophilic cytoplasm and small nuclei with irregular contours and indistinct to small nucleoli (a). Foamy histiocytes were seen within fibrovascular cores of papillae (b) and psammoma bodies were present (c). The tumor from patient 2 primarily showed papillary structures and cells with clear to eosinophilic cytoplasm, similar to the features seen in the tumor from patient 1 (d). In addition, the tumor showed regions with papillae lined by small cuboidal cells with scant cytoplasm (e) as well as areas of solid growth, with cells showing primarily eosinophilic cytoplasm, larger nuclei, and more prominent nucleoli (f). The transition between areas with distinct morphology was abrupt (g), however rearrangement of $A L K$ was uniform throughout the tumor. 

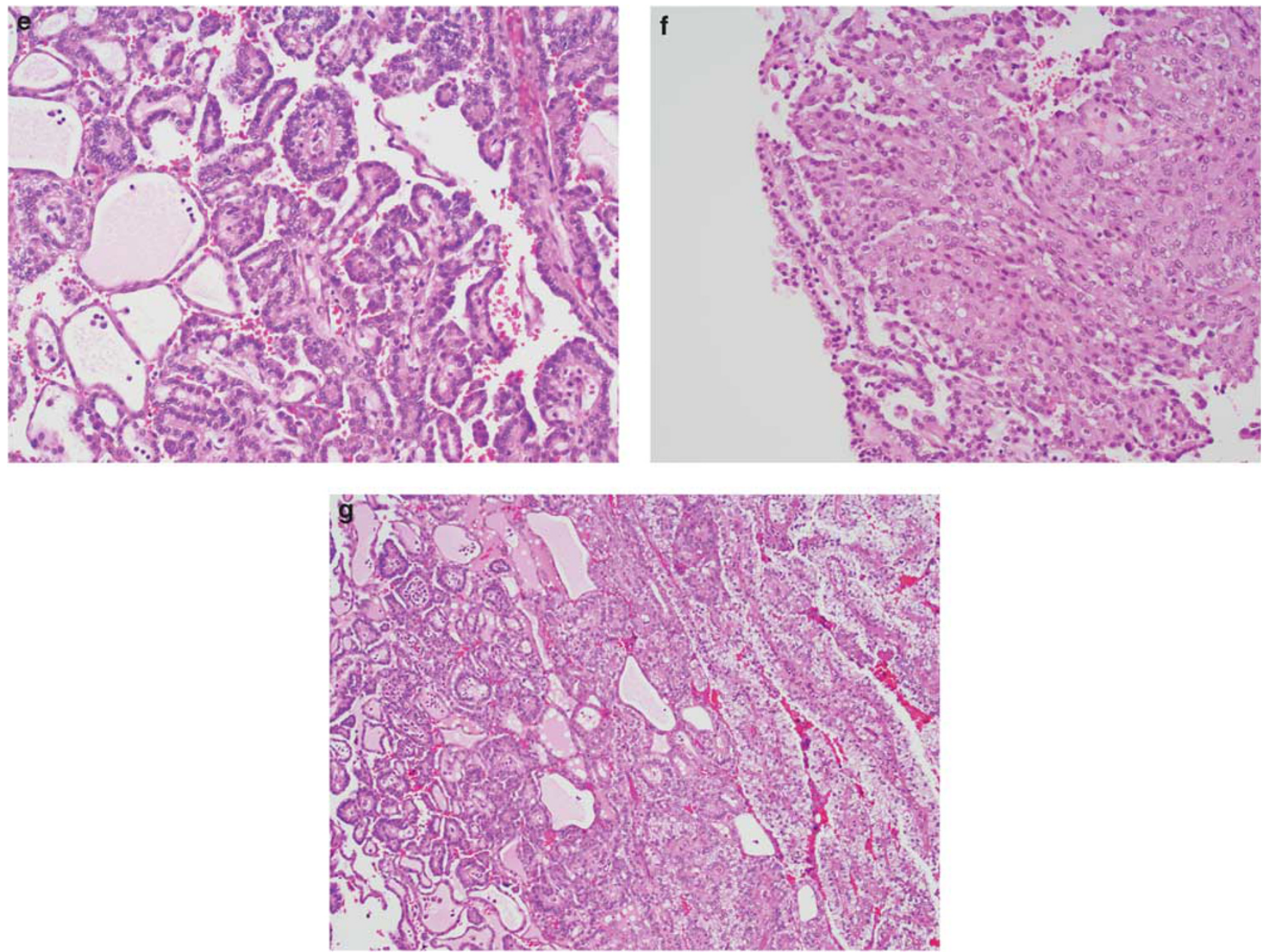

Figure 2 Continued.

demonstrated overexpression of ALK protein in both tumors, with weak cytoplasmic staining in the tumor from patient 1 and moderate to focally strong cytoplasmic staining in the tumor from patient 2 . Both tumors also showed strong positivity for keratin 7, P504S, AE1/AE3, vimentin and CAM5.2, focal staining for CD10, and were negative for Napsin A, HMB45, and Melan A. Both tumors were negative for TFE3 rearrangement by FISH.

\section{ALK Copy Number Gains}

$A L K$ copy number was also assessed in 532 CCRCC and PRCC ( $A L K$-rearranged tumors were excluded). Among 250 CCRCC, 146 (58\%) demonstrated 2F signals ( 2 intact $A L K$ loci) in $\geq 95 \%$ of nuclei, 62 $(25 \%)$ had $3-4 \mathrm{~F}$ signals present in $\geq 5 \%$ of nuclei, and $42(17 \%)$ had $\geq 5 \mathrm{~F}$ signals (range $5 \mathrm{~F}-11 \mathrm{~F}$; median $6 \mathrm{~F}$ ) in $\geq 5 \%$ of nuclei. Among the 282 PRCC, similar signals were identified in 211 (74\%), $59(21 \%)$, and $12(4 \%)$, respectively. Of the PRCC with $\geq 5 \mathrm{~F}$ signals, the range of signals was $5 \mathrm{~F}$ to $10 \mathrm{~F}$ with a median of $6 \mathrm{~F}$. The distribution of $A L K$ copy number gains differed significantly between patients with CCRCC and PRCC $(P<0.001)$.

\section{Clear Cell Renal Cell Carcinoma}

Comparisons of $A L K$ gene copy number gains to clinical and pathological features for the 250 patients with CCRCC are summarized in Table 2. The presence of $A L K$ gain by FISH was significantly associated with tumor size and nuclear grade. For example, only $36 \%$ of the patients with $2 \mathrm{~F}$ signals in all nuclei had high-grade tumors compared with the higher rate of $47 \%$ of the patients with $3-4 \mathrm{~F}$ signals in $\geq 5 \%$ of nuclei and $79 \%$ of the patients with $\geq 5 \mathrm{~F}$ signals in $\geq 5 \%$ of nuclei $(P<0.001)$.

At last follow-up, 180 patients with CCRCC died at a mean of 7.0 years following surgery (median 6.4; range 0-20). Among the 70 patients still alive at last follow-up, the mean duration of follow-up was 15.9 years (median 16.8; range 0-21). Five patients died from unknown causes and could not be included in the analyses of cancer-specific survival. Of the remaining 245 patients, 90 died from RCC at a mean 
Table 2 Comparison of ALK copy number gain with clinical and pathological features for 250 patients with clear cell type renal cell carcinoma

\begin{tabular}{|c|c|c|c|c|}
\hline & \multicolumn{3}{|c|}{ ALK copy number gain } & \multirow[b]{2}{*}{ P-value } \\
\hline & $2 F(\mathrm{~N}=146)$ & $3-4 F(\mathrm{~N}=62)$ & $\geq 5 F(\mathrm{~N}=42)$ & \\
\hline Feature & & Mean (median; range) & & \\
\hline Age at surgery (years) & $62.6(64 ; 32-85)$ & $62.0(64 ; 35-84)$ & $62.9(66 ; 37-83)$ & 0.85 \\
\hline Tumor size $(\mathrm{cm} ; N=249)$ & $6.5(5.8 ; 1.0-18.0)$ & $6.9(6.0 ; 1.0-22.0)$ & $7.9(6.8 ; 3.7-16.0)$ & 0.017 \\
\hline Gender & & $N(\%)$ & & \\
\hline Female & $58(40)$ & $24(39)$ & $12(29)$ & 0.41 \\
\hline Male & $88(60)$ & $38(61)$ & $30(71)$ & \\
\hline Symptoms & $97(66)$ & $42(68)$ & $33(79)$ & 0.32 \\
\hline Constitutional symptoms & $37(25)$ & $17(27)$ & $15(36)$ & 0.42 \\
\hline \multicolumn{5}{|c|}{2010 primary tumor classification $(\mathrm{N}=249)$} \\
\hline pT1a & $48(33)$ & $13(21)$ & $2(5)$ & 0.020 \\
\hline pT1b & $35(24)$ & $19(31)$ & $15(36)$ & \\
\hline pT2a & $13(9)$ & $8(13)$ & $6(14)$ & \\
\hline pT2b & $9(6)$ & $3(5)$ & $3(7)$ & \\
\hline рТ3а & $28(19)$ & $13(21)$ & $12(29)$ & \\
\hline pT3b & $9(6)$ & $4(6)$ & $2(5)$ & \\
\hline pT3c & $3(2)$ & $2(3)$ & 0 & \\
\hline $\mathrm{pT} 4$ & 0 & 0 & $2(5)$ & \\
\hline \multicolumn{5}{|c|}{2010 primary tumor classification $(\mathrm{N}=249)$} \\
\hline pT1, pT2 & $105(72)$ & $43(69)$ & $26(62)$ & 0.42 \\
\hline pT3, pT4 & $40(28)$ & $19(31)$ & $16(38)$ & \\
\hline \multicolumn{5}{|c|}{2010 regional lymph node involvement } \\
\hline pNX & $110(75)$ & $52(84)$ & $26(62)$ & 0.13 \\
\hline pNo & $30(21)$ & $8(13)$ & $14(33)$ & \\
\hline $\mathrm{pN} 1$ & $6(4)$ & $2(3)$ & $2(5)$ & \\
\hline \multicolumn{5}{|l|}{ Distant metastases } \\
\hline Mo & $134(92)$ & $56(90)$ & $37(88)$ & 0.76 \\
\hline M1 & $12(8)$ & $6(10)$ & $5(12)$ & \\
\hline \multicolumn{5}{|l|}{ Nuclear grade } \\
\hline 1 & $19(13)$ & $3(5)$ & $1(2)$ & $<0.001$ \\
\hline 2 & $75(51)$ & $30(48)$ & $8(19)$ & \\
\hline 3 & $40(27)$ & $28(45)$ & $23(55)$ & \\
\hline 4 & $12(8)$ & $1(2)$ & $10(24)$ & \\
\hline \multicolumn{5}{|l|}{ Nuclear grade } \\
\hline 1,2 & $94(64)$ & $33(53)$ & $9(21)$ & $<0.001$ \\
\hline 3,4 & $52(36)$ & $29(47)$ & $33(79)$ & \\
\hline Coagulative tumor necrosis & $39(27)$ & $15(24)$ & $18(43)$ & 0.08 \\
\hline Sarcomatoid differentiation & $7(5)$ & $1(2)$ & $2(5)$ & 0.66 \\
\hline Multifocality & $9(6)$ & $1(2)$ & 0 & 0.19 \\
\hline SSIGN scores & $3.4(2.5 ; 0-14)$ & $3.6(3 ; 0-11)$ & $5.3(5 ; 0-11)$ & $<0.001$ \\
\hline
\end{tabular}

Abbreviation: ALK, anaplastic lymphoma kinase.

of 4.8 years following the surgery (median 3.0; range 0-18). Overall and cancer-specific survival rates (95\% CI; number still at risk) at 10 years following surgery were $50 \%(44-57 ; 122)$ and $67 \%(62-74$; 118), respectively.

Among the patients with $2 \mathrm{~F}, 3-4 \mathrm{~F}$, and $\geq 5 \mathrm{~F}$ signals, there were 99,47 , and 34 deaths, respectively, including 45, 23, and 22 deaths from RCC. Overall survival rates (95\% CI; number still at risk) at 10 years following surgery for patients with $2 \mathrm{~F}$, $3-4 \mathrm{~F}$, and $\geq 5 \mathrm{~F}$ signals were $52 \%$ (44-60; 73$)$, $55 \%$
(44-69; 33), and 38\% (26-56; 16), respectively $(P=0.35)$. Cancer-specific survival rates $(95 \% \mathrm{CI}$; number still at risk) at 10 years following surgery for patients with $2 \mathrm{~F}, 3-4 \mathrm{~F}$, and $\geq 5 \mathrm{~F}$ signals were $72 \%$ (64-80; 70), 69\% (58-83; 32), and 52\% (38-70; 16), respectively. Although the difference in cancerspecific survival among all three groups did not reach statistical significance $(P=0.07)$, the cancerspecific survival was significantly worse for patients with $\geq 5 \mathrm{~F}$ signals compared with those with $2 \mathrm{~F}$ and $3-4 \mathrm{~F}$ signals combined. Specifically, the 10-year 


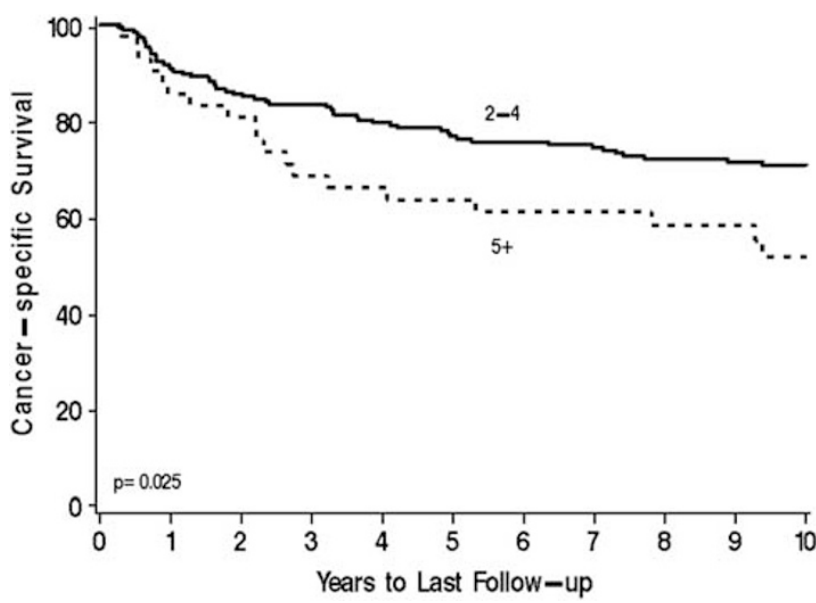

Figure 3 Cancer-specific survival by anaplastic lymphoma kinase $(A L K)$ copy number gain for 250 patients with clear cell renal cell carcinoma (CCRCC) classified into two groups of 2-4 copies and $\geq 5$ copies of $A L K$. Patients with tumors classified as having $\geq 5$ copies compared with 2-4 copies had a significantly worse outcome $(P=0.025)$.

cancer-specific survival rate (95\% CI; number still at risk) for patients in the combined $2-4 \mathrm{~F}$ group was $71 \%(64-78 ; 102)$ compared with $52 \%(38-70 ; 16)$ for patients in the $\geq 5 \mathrm{~F}$ signal group $(P=0.025$; Figure 3). This is also demonstrated by the hazard ratio for the association of $\geq 5 \mathrm{~F}$ signals with death from CCRCC, which was 1.72 (95\% CI 1.07-2.79; $P=0.025$ ), indicating that patients with a tumor showing $\geq 5$ intact $A L K$ signals were $72 \%$ more likely to die from RCC compared with patients whose tumor showed 2-4 ALK copies. However, this difference was no longer statistically significant after adjusting for nuclear grade (hazard ratio 0.87; 95\% CI 0.54-1.43; $P=0.59$ ). Similarly, after adjusting for the SSIGN score, the hazard ratio for the association of 5 $+\mathrm{F}$ signals with death from RCC was 1.31 (95\% CI $0.81-2.13 ; P=0.27$ ).

\section{Papillary Renal Cell Carcinoma}

Comparisons of $A L K$ copy number gains with clinical and pathological features for the 282 patients with PRCC (after excluding the two patients with $A L K$ rearrangement) are summarized in Table 3. ALK copy number gains were significantly associated with patient gender; 88 and $86 \%$ of patients in the $2 \mathrm{~F}$ and $3-4 \mathrm{~F}$ groups were male compared with $50 \%$ of patients with $\geq 5 \mathrm{~F}(P=0.001)$.

At last follow-up, 162 patients with PRCC died at a mean of 7.8 years following surgery (median 6.0; range 0-35). Among the 120 patients still alive at last follow-up, the mean duration of follow-up was 12.6 years (median 11.9; range $0-39$ ). Five patients died from unknown causes and could not be included in analyses of cancer-specific survival. Of the remaining 277 patients, 34 died from RCC at a mean of 3.4 years following surgery (median 2.7; range 0-17). Overall and cancer-specific survival rates (95\% CI; number still at risk) at 10 years following surgery were $60 \%(54-66 ; 135)$ and $86 \%$ (82-91; 133), respectively.

Among patients in the $2 \mathrm{~F}, 3-4 \mathrm{~F}$, and $\geq 5 \mathrm{~F}$ tumor groups, there were 130, 25, and 7 deaths, respectively, including 28, 4, and 3 deaths from RCC. Overall survival rates (95\% CI; number still at risk) at 10 years following surgery for patients in the $2 \mathrm{~F}$, $3-4 \mathrm{~F}$, and $\geq 5 \mathrm{~F}$ tumor groups were $58 \%$ (51-65; 99), $71 \%(60-84 ; 30)$, and $50 \%(28-88 ; 6)$, respectively $(P=0.19)$. Cancer-specific survival rates $(95 \% \mathrm{CI}$; number still at risk) at 10 years following surgery for patients in the $2 \mathrm{~F}, 3-4 \mathrm{~F}$, and $\geq 5 \mathrm{~F}$ tumor groups were $85 \%(79-90 ; 97), 93 \%(86-100 ; 30)$, and $80 \%(59-$ $100 ; 6)$, respectively $(P=0.33)$. The 10 -year cancerspecific survival rate (95\% CI; number still at risk) for patients with 2-4 $A L K$ signals was $87 \%$ (82-91; 127) compared with $80 \%(59-100 ; 6)$ for patients with $\geq 5$ ALK signals $(P=0.55)$.

\section{Discussion}

Based on recent clinical studies in lung adenocarcinoma, the ALK tyrosine kinase receptor is a promising target for directed therapy with crizotinib, an inhibitor of ALK and ALK-variant proteins resulting from rearrangement of the $A L K$ locus. ${ }^{15-17}$ Therefore, the identification of $A L K$ rearrangements in other tumor types has gained importance owing to the potential for a similar treatment response. ${ }^{19}$ Rearrangement of $A L K$ has recently been reported in pediatric RCC. ${ }^{20,21}$ However, to our knowledge, no study has yet studied $A L K$ alterations in a large series of adult RCC. The goal of the present study was to comprehensively analyze alterations of the $A L K$ locus, specifically rearrangements and copy number gain, in adult RCC to identify the frequency and nature of $A L K$ alterations and to determine if there was a relationship between these alterations and clinical or pathological findings and/or clinical behavior. This was accomplished by screening tumors from a large population of adult patients consecutively treated by surgery at Mayo Clinic for either PRCC or CCRCC.

We identified rearrangement of the $A L K$ locus in 2 of 534 adult RCC, representing $<1 \%$ of all RCC and $2 \%$ of all PRCC studied, suggesting that $A L K$ rearranged tumors characterize a small proportion of adult RCC. Both patients with RCC harboring $A L K$ rearrangements had a poor clinical outcome, dying from disease in $<5$ years, despite having a low stage at the time of original surgery, suggesting that these RCCs may be an aggressive subset. The tumors from both showed similar and distinctive histological features and were defined primarily by a papillary architecture populated by cells with clear to eosinophilic cytoplasm. By immunohistochemistry, these tumors demonstrated a phenotype consistent with PRCC, showing the expression of keratin 7 and P504S. Recent studies have also defined a group of 
Table 3 Comparison of $A L K$ copy number gain with clinical and pathologic features for 282 patients with papillary type renal cell carcinoma

\begin{tabular}{|c|c|c|c|c|}
\hline & & ALK copy number gain & & \\
\hline & $2 F(\mathrm{~N}=211)$ & $3-4 F(\mathrm{~N}=59)$ & $\geq 5 F(\mathrm{~N}=12)$ & $\mathrm{P}$-value \\
\hline Feature & & Mean (median; range) & & \\
\hline Age at surgery (years) & $64.1(66 ; 30-89)$ & $62.2(64 ; 34-82)$ & $67.3(65 ; 52-82)$ & 0.45 \\
\hline Tumor size $(\mathrm{cm} ; N=279)$ & $5.5(4.0 ; 0.6-24.5)$ & $5.1(3.8 ; 1.2-16.0)$ & $5.4(4.3 ; 2.5-10.0)$ & 0.71 \\
\hline Gender & & $N(\%)$ & & \\
\hline Female & $25(12)$ & $8(14)$ & $6(50)$ & 0.001 \\
\hline Male & $186(88)$ & $51(86)$ & $6(50)$ & \\
\hline Symptoms & $117(55)$ & $28(47)$ & $7(58)$ & 0.53 \\
\hline Constitutional symptoms & 37 (18) & $7(12)$ & $3(25)$ & 0.43 \\
\hline 2010 primary tumor classifi & $=280)$ & & & \\
\hline pT1a & $103(49)$ & $30(51)$ & $6(60)$ & 0.97 \\
\hline pT1b & $44(21)$ & $14(24)$ & $3(25)$ & \\
\hline pT2a & $18(9)$ & $8(14)$ & $2(17)$ & \\
\hline pT2b & $17(8)$ & $2(3)$ & 0 & \\
\hline рТ3а & $19(9)$ & $4(7)$ & $1(8)$ & \\
\hline pT3b & $6(3)$ & $1(2)$ & 0 & \\
\hline pT3c & $1(<1)$ & 0 & 0 & \\
\hline pT4 & $1(<1)$ & 0 & 0 & \\
\hline 2010 primary tumor classifi & $=280)$ & & & \\
\hline pT1, pT2 & $182(87)$ & $54(92)$ & $11(92)$ & 0.60 \\
\hline pT3, pT4 & $27(13)$ & $5(8)$ & $1(8)$ & \\
\hline 2010 regional lymph node it & & & & \\
\hline pNX & $184(87)$ & $50(85)$ & $10(83)$ & 0.80 \\
\hline pNo & $16(8)$ & $6(10)$ & $1(8)$ & \\
\hline $\mathrm{pN} 1$ & $11(5)$ & $3(5)$ & $1(8)$ & \\
\hline Distant metastases & & & & \\
\hline Mo & $205(97)$ & $56(95)$ & $12(100)$ & 0.61 \\
\hline M1 & $6(3)$ & $3(5)$ & 0 & \\
\hline Nuclear grade & & & & \\
\hline 1 & $3(1)$ & 0 & 0 & 0.18 \\
\hline 2 & $129(61)$ & $33(56)$ & $4(33)$ & \\
\hline 3 & $74(35)$ & $26(44)$ & $7(58)$ & \\
\hline 4 & $5(2)$ & 0 & $1(8)$ & \\
\hline Nuclear grade & & & & \\
\hline 1,2 & $132(63)$ & $33(56)$ & $4(33)$ & 0.10 \\
\hline 3,4 & $79(37)$ & $26(44)$ & $8(67)$ & \\
\hline Coagulative tumor necrosis & $101(48)$ & $29(49)$ & $10(83)$ & 0.06 \\
\hline Sarcomatoid differentiation & $4(2)$ & 0 & $1(8)$ & 0.18 \\
\hline Multifocality & $24(11)$ & $5(8)$ & $1(8)$ & 0.79 \\
\hline
\end{tabular}

Abbreviations: ALK, anaplastic lymphoma kinase.

RCC with architectural features of PRCC but comprised largely of cells with clear cytoplasm similar to our $A L K$-rearranged RCCs. ${ }^{22} \mathrm{~A}$ subset of these PRCC harbor either TFE3 or TFEB translocations. However, both tumors with $A L K$ rearrangements in this study were tested for concurrent rearrangements of TFE3 by FISH and were negative. We did not test for rearrangements of TFEB, and therefore a concurrent alteration of this locus cannot be excluded. Also, recent studies have identified a subset of RCCs with similar histological features that show overlap with periepithelioid cell tumors. ${ }^{23}$ Although the two tumors in this series showed little overlap with the features of PEComa, we also performed immunohistochemistry for Melan A and HMB45, which were negative in both tumors. It will be important to identify and study additional patients with RCCs harboring $A L K$ rearrangements to determine if tumors with $A L K$ rearrangement represent a more aggressive subset of RCC and to further define a relationship between $A L K$ rearrangement and histological features.

The presence of $A L K$ rearrangement in a certain subset of adult RCCs may be quite significant, given the possibility that such tumors may be sensitive to therapy with the ALK inhibitor criztuzimab. This treatment option becomes even more significant if 
$A L K$ rearrangement is indeed associated with a more aggressive subset of RCC. The frequency of $A L K$ rearranged RCC appears very small, making general screening of adult RCCs unrealistic. It may be that the histological features can be used to identify RCCs with a higher likelihood of harboring $A L K$ rearrangements and therefore substantially diminish the number of tumors that need to be tested. Additionally, as both $A L K$-rearranged tumors showed overexpression of ALK, immunohistochemistry may be utilized in tumors with suspicious morphology to identify RCCs that may respond to ALK inhibitors, with subsequent FISH testing providing confirmation of $A L K$ rearrangement.

The presence of additional copies of the $A L K$ locus is a frequent finding in lung adenocarcinoma; however, the significance of this finding has yet to be determined. In the current study, our goal was to comprehensively study alterations of the ALK locus in adult RCC. Therefore, we also evaluated tumors for gain of $A L K$ copy number. Each tumor (excluding the two tumors with $A L K$ rearrangement) was defined by the highest $A L K$ copy number present in at least $5 \%$ of tumor cells. This $5 \%$ cut point was chosen to account for intratumoral heterogeneity with regard to $A L K$ copy number and was based in part on criteria used for HER2 testing in breast cancer. ${ }^{24}$ Tumors were assigned to one of three copy number groups: the $2 \mathrm{~F}$ (normal copy number) group, the $3-4 \mathrm{~F}$ group, or the $\geq 5 \mathrm{~F}$ group. The behavior of tumors in the normal copy number group should not be influenced by $A L K$. Similarly, the presence of one or two additional $A L K$ copies (three or four in total) is not likely to be a functionally important gain of $A L K$, probably reflecting either trisomy of chromosome 2 or tetraploidization as may be seen in dividing cells. However, the presence of $\geq 5$ copies of $A L K$ suggests that additional gene copies may have a functional role in oncogenesis. This concept has been established for HER2 testing in breast cancer and MYCN testing in neuroblastoma, although the cutoffs used in our current study vary somewhat from those that define 'copy number gain' or 'amplification' in HER2 and NMYC testing. ${ }^{25,26}$

We identified 54 RCCs with ALK copy number gain ( $\geq 5$ copies). We also identified an association between the presence of $\geq 5$ copies of $A L K$ and a poorer cancer-specific survival in patients with CCRCC but not in PRCC. The presence of increased $A L K$ copy number was also significantly associated with prognostic factors including increased tumor size and nuclear grade in CCRCC. However, when adjusted for nuclear grade, the association did not remain significant. This may reflect a role of ALK in tumor progression, which is reflected as a higher tumor nuclear grade. However, it is more likely that this association simply reflects the association between larger nuclear size (reflected in nuclear grade) and an overall increase in chromosome copy number unrelated to the function of
ALK per se. Further study is needed to determine if additional intact copies of $A L K$ have a pathogenic role in RCC, and consequently whether patients with such tumors can benefit from directed ALK inhibitor therapy.

In conclusion, we present, what is to our knowledge, the first study to characterize $A L K$ rearrangements and copy number gain in a large series of adult patients treated consecutively for RCC. Our findings indicate that $A L K$ rearrangement is a rare finding in adult RCC but may be associated with distinct histological features and a poor outcome. Patients with RCC harboring $A L K$ rearrangements may benefit from ALK inhibitor therapy and based on the present findings, this subset of tumors may be identifiable based histological and immunophenotypical features.

\section{Disclosure/conflict of interest}

The authors declare no conflict of interest.

\section{References}

1 Morris SW, Kirstein MN, Valentine MB, et al. Fusion of a kinase gene, ALK, to a nucleolar protein gene, NPM, in non-Hodgkin's lymphoma. Science 1994;263: 1281-1284.

2 Iwahara T, Fujimoto J, Wen D, et al. Molecular characterization of ALK, a receptor tyrosine kinase expressed specifically in the nervous system. Oncogene 1997;14:439-449.

3 Lin E, Li L, Guan Y, et al. Exon array profiling detects EML4-ALK fusion in breast, colorectal, and non-small cell lung cancers. Mol Cancer Res 2009;7:1466-1476.

4 Dirks WG, Fahnrich S, Lis Y, et al. Expression and functional analysis of the anaplastic lymphoma kinase (ALK) gene in tumor cell lines. Int J Cancer 2002; 100:49-56.

5 Lawrence B, Perez-Atayde A, Hibbard $\mathrm{MK}$, et al. TPM3-ALK and TPM4-ALK oncogenes in inflammatory myofibroblastic tumors. Am J Pathol 2000;157: 377-384.

6 Ma Z, Cools J, Marynen P, et al. Inv(2)(p23q35) in anaplastic large-cell lymphoma induces constitutive anaplastic lymphoma kinase (ALK) tyrosine kinase activation by fusion to ATIC, an enzyme involved in purine nucleotide biosynthesis. Blood 2000;95: 2144-2149.

7 Bridge JA, Kanamori M, Ma Z, et al. Fusion of the ALK gene to the clathrin heavy chain gene, CLTC, in inflammatory myofibroblastic tumor. Am J Pathol 2001;159:411-415.

8 Gascoyne RD, Lamant L, Martin-Subero JI, et al. ALKpositive diffuse large B-cell lymphoma is associated with Clathrin-ALK rearrangements: report of 6 cases. Blood 2003;102:2568-2573.

9 Soda M, Choi YL, Enomoto M, et al. Identification of the transforming EML4-ALK fusion gene in non-smallcell lung cancer. Nature 2007;448:561-566.

10 Chiarle R, Voena C, Ambrogio C, et al. The anaplastic lymphoma kinase in the pathogenesis of cancer. Nat Rev Cancer 2008;8:11-23. 
11 Kuefer MU, Look AT, Pulford K, et al. Retrovirusmediated gene transfer of NPM-ALK causes lymphoid malignancy in mice. Blood 1997;90:2901-2910.

12 Martinelli P, Bonetti P, Sironi C, et al. The lymphomaassociated NPM-ALK oncogene elicits a p16INK4a/ pRb-dependent tumor-suppressive pathway. Blood 2011;117:6617-6626.

13 Young LC, Bone KM, Wang P, et al. Fusion tyrosine kinase NPM-ALK Deregulates MSH2 and suppresses DNA mismatch repair function novel insights into a potent oncoprotein. Am J Pathol 2011;179: 411-421.

14 Rikova K, Guo A, Zeng Q, et al. Global survey of phosphotyrosine signaling identifies oncogenic kinases in lung cancer. Cell 2007;131:1190-1203.

15 Kwak EL, Bang YJ, Camidge DR, et al. Anaplastic lymphoma kinase inhibition in non-small-cell lung cancer. N Engl J Med 2010;363:1693-1703.

$16 \mathrm{Ou}$ SH, Bazhenova L, Camidge DR, et al. Rapid and dramatic radiographic and clinical response to an ALK inhibitor (crizotinib, PF02341066) in an ALK translocation-positive patient with non-small cell lung cancer J Thorac Oncol 2010;5:2044-2046.

$17 \mathrm{Ou} \mathrm{SH}$, Kwak EL, Siwak-Tapp C, et al. Activity of crizotinib (PF02341066), a dual mesenchymal-epithelial transition (MET) and anaplastic lymphoma kinase (ALK) inhibitor, in a non-small cell lung cancer patient with de novo MET amplification. J Thorac Oncol 2011;6:942-946.

18 Frank I, Blute ML, Cheville JC, et al. An outcome prediction model for patients with clear cell renal cell carcinoma treated with radical nephrectomy based on tumor stage, size, grade and necrosis: the SSIGN score. J Urol 2002;168:2395-2400.

19 Butrynski JE, D’Adamo DR, Hornick JL, et al. Crizotinib in ALK-rearranged inflammatory myofibroblastic tumor. N Engl J Med 2010;363:1727-1733.

20 Marino-Enriquez A, Ou WB, Weldon CB, et al. ALK rearrangement in sickle cell trait-associated renal medullary carcinoma. Genes Chromosomes Cancer 2011;50:146-153.

21 Debelenko LV, Raimondi SC, Daw N, et al. Renal cell carcinoma with novel VCL-ALK fusion: new representative of ALK-associated tumor spectrum. Mod Pathol 2011;24:430-442.

22 Klatte T, Said JW, Seligson DB, et al. Pathological, immunohistochemical and cytogenetic features of papillary renal cell carcinoma with clear cell features. J Urol 2011;185:30-35.

23 Argani P, Aulmann S, Illei PB, et al. A distinctive subset of PEComas harbors TFE3 gene fusions. AmJ Surg Pathol 2010;34:1395-1406.

24 Vance GH, Barry TS, Bloom KJ, et al. Genetic heterogeneity in HER2 testing in breast cancer: panel summary and guidelines. Arch Pathol Lab Med 2009;133:611-612.

25 Wolff AC, Hammond ME, Schwartz JN, et al. American Society of Clinical Oncology/College of American Pathologists guideline recommendations for human epidermal growth factor receptor 2 testing in breast cancer. J Clin Oncol 2007;25:118-145.

26 Ambros PF, Ambros IM, Brodeur GM, et al. International consensus for neuroblastoma molecular diagnostics: report from the International Neuroblastoma Risk Group (INRG) Biology Committee. Br J Cancer 2009;100:1471-1482. 